\title{
PROFILING OF PROTON BEAMS BY FLUENCE SCANNERS
}

\author{
L. Deveikis ${ }^{\text {a }}$, J.V. Vaitkus a, T. Čeponis ${ }^{\text {a }}$, M. Gaspariūnas ${ }^{\text {b }}$, V. Kovalevskij ${ }^{\text {a, b}}$, \\ V. Rumbauskas ${ }^{a}$, and E. Gaubas ${ }^{a}$ \\ ${ }^{a}$ Institute of Photonics and Nanotechnology, Vilnius University, Sauletekio 3, 10257 Vilnius \\ ${ }^{\mathrm{b}}$ Centre for Physical Sciences and Technology, Sauletekio 3, 10257 Vilnius \\ Email: laimonas.deveikis@tmi.vu.lt
}

Received 6 April 2021; accepted 15 April 2021

\begin{abstract}
Profiling of particle beams is one of the most important diagnostic procedures for operating any kind of accelerator. In this work, the proton beam profilers, based on fluence measurements performed by recording the changes of carrier lifetime in Si material and scintillation intensity of thin GaN layers, caused by radiation induced defects and emission centres, are presented. The beams of penetrative $(26 \mathrm{GeV} / \mathrm{c})$ and stopped $(1.6 \mathrm{MeV})$ protons have been examined. It is shown that the penetrative particle regime should be employed to appropriately record $2 \mathrm{D}$ fluence distribution profiles. It is also illustrated that the presented profiling techniques can be applied for scanning of other charged (namely, pions) and neutral (neutrons) particle beams.
\end{abstract}

Keywords: particle beam profiling, carrier lifetime, microwave probed photoconductivity, luminescence, scintillators

PACS: $29.27 .-\mathrm{a}, 29.40 . \mathrm{Mc}, 72.40 .+\mathrm{w}, 78.60 .-\mathrm{b}$

\section{Introduction}

Profiling of particle beams is one of the essential radiation diagnostic procedures for governing any kind of accelerator. The profile measurement principles are mainly based on either coupling to the particle electromagnetic field, which is freely propagating as radiation, or on the energy deposition due to the interaction of the particle electromagnetic field with matter [1-3]. As concerns the freely propagating fields, depending on the separation mechanism associated with coupling of the electromagnetic field and moving particles, different types of radiation such as synchrotron, transition, diffraction, parametric X ray, Cherenkov, and Smith-Purcell radiation are considered [1]. Radiation generation can be understood in terms of a separation of the virtual photon field associated with the charged particle. The most common of them are the meth- ods based on transition radiation [4-8] and scintillation [1, 8, 9] of various materials. A broad band electromagnetic radiation, named transition radiation, is produced when a charged particle passes the boundary between two media with different dielectric constants [1, 7]. The wide frequency range radiation from $\mathrm{THz}$ to $\mathrm{X}$ rays is emitted on both sides of a conductive foil. This transition radiation originates from the currents induced on the foil by moving charged particles and by timevarying surface currents 泡. The visible spectrum of this radiation (optical transition radiation, OTR) is predominantly considered, and the recorded intensity profile is a measure of the particle beam spot. Thereby, the OTR recording is beneficial in that it allows fast single shot beam profile measurements, and the radiation output scales linearly with the particle beam bunch intensity [1]]. The transition radiation measurement instrumentation is 
usually implemented using a thin aluminium foil deposited on dielectrics. Alternatively, secondary electron emission (SEE) from a few nanometre layer next to the surface of the thin films can be employed for a beam profiling [ [T]. This ultra-thin layer is deposited on membrane and can afford high absorbed doses. The transverse beam profiles are controlled in monitoring of functioning of an accelerator and halo formation prevention [5]. The accelerated particles are typically distributed according to the Gaussian function within transverse beam profiles [3, 使. The large energy deposition can lead to the destruction of profiler sensor materials. Therefore, usage of the traditional multi-wire chambers and wire scanners [3] is limited within inspection of the high repetition rates of pulsed beams and especially for continuous beam operation [5]. The recombination of the secondary carrier pairs produced by the passage of a charged particle leads to the generation of scintillation signals [3]. This material de-excitation process usually involves many metastable levels. Different types of phosphor materials have been developed to obtain large scintillation yields [3, 9, 10]. Generation of the laser-accelerated pulsed proton beams comprises the basis of the modern technologies in radiation biology and therapy [1, 10]. Profiling of these beams is inevitable due to the broad angular divergence of the laser-accelerated proton beams and stringent requirements on dose homogeneity and total flux at the irradiated body [10]. However, traditional beam profiling techniques are based on scanning of the flux lateral distribution due to the interaction of the particle electromagnetic field with matter [1-3], while local dose rates and accumulated fluence are the most important characteristics in radiation therapy.

In this work, the proton beam profilers, based on fluence measurements performed by recording the changes of carrier lifetime in Si material and scintillation intensity of thin GaN layers, caused by radiation induced defects and emission centres, are discussed. The measured beam parameters and scanned profiles are compared with those extracted using traditional beam profile monitors installed at CERN. The beams of penetrative $(26 \mathrm{GeV} / \mathrm{c})$ and stopped $(1.6 \mathrm{MeV})$ protons have been examined. The prospects of the proposed techniques for direct profiling of doses within proton beams have been shown. It has been illus- trated that these profiling techniques can be applied for scanning of other charged (namely, pions) and neutral (neutrons) particle beams.

\section{Principles of techniques and instruments for fluence scanning}

The deposited energy of irradiation may create defects in materials used for radiation detection. Probing of these radiation defects - either the centres of radiative recombination, modifying dose dependent scintillation intensity, or the induced non-radiative carrier decay processes, changing carrier lifetime - serves for measurement of irradiation fluence and its distribution within particle beams. In this work, both the scintillation and nonradiative response signals have been exploited for profiling of proton beams.

\subsection{Scanning of carrier lifetime distribution within irradiated Si wafers}

Rather universal dependence (Fig. 1) of the carrier recombination lifetime $\left(\tau_{\mathrm{R}}\right)$ in high purity, large resistivity silicon materials as a function of hadron irradiation fluence $(\Phi)$ has been revealed [11]. Si materials grown either by the float zone (FZ) or Czochralski applying magnetic field (MCZ) technology are the most suitable for reliable detection of this characteristic. This dependence can be employed for detection of penetrative hadrons the stopping range $L_{\mathrm{p}}$ of which exceeds the sample thickness $d$.

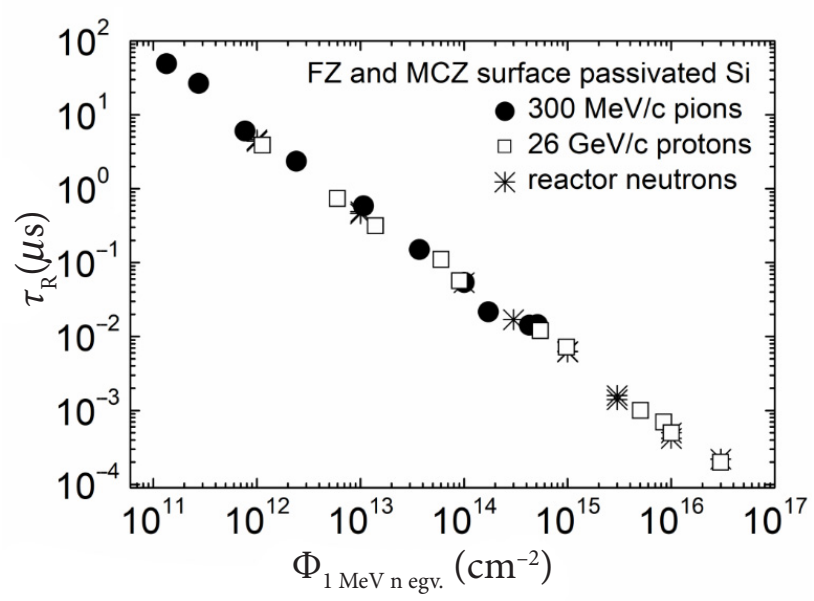

Fig. 1. Typical dependence of the recombination lifetime as a function of the penetrative hadron irradiation fluence obtained on high purity (FZ and MCZ) and surface passivated $S i$ wafer fragments. 
Rather thick $(d \sim 300 \mu \mathrm{m})$ Si wafers or wafer fragments are usually employed to integrate a response from the relevant density of recombination centres. The reciprocal characteristic of $\tau_{\mathrm{R}}-\Phi$ is obtained within a double logarithmic scale. This characteristic indicates the hyperbolic dependence and the prevalence of point radiation defects: for those the linear relation between the defect concentration $\left(N_{\mathrm{R}}\right)$ and recombination rate $R=1 / \tau_{\mathrm{R}}=\sigma v_{T} N_{\mathrm{R}}$ exists, where $\sigma$ is the cross-section of interaction of the carriers with a definite type of recombination centres, and $v_{T}$ is the thermal velocity of carriers. The linear $\log \tau_{\mathrm{R}}-$ $\log \Phi$ characteristic (Fig. 11) covers about 6 orders of magnitude. Either the surface passivated large resistivity silicon material should be used or corrections due to surface recombination velocity $(s)$ are necessary when $\tau_{\mathrm{R}} \geq d / s$. The corrections relatively to excess carrier injection rate also should be made in the range of the largest irradiation fluences if the excess carrier excitation pulses of moderate duration ( $\sim \mathrm{ns})$ are employed. The exponential decay is usually observed in the as-irradiated Si materials. Therefore, the carrier lifetime values are extracted using the photoconductivity decay transients, as $\tau_{\mathrm{R}}=n /\left.(-\partial n / \partial t)\right|_{\exp (-1)}$. The contactless MW-PC technique of the microwave (MW) probed photoconductivity (PC) is commonly applied for carrier lifetime measurements [11].

The FZ Si wafer fragments of $30 \times 30 \mathrm{~mm}$ dimensions (Fig. 2(a)) irradiated with $26 \mathrm{GeV} / \mathrm{c}$ protons at CERN were scanned with $2 \mu \mathrm{m}$ step to reproduce the initial particle beam profile. The carrier lifetime profiling has been performed in dark using a Vilnius University proprietary made instrument VUTEG-4 (Fig. 2(b)). This instrument enables 2D scanning of Si wafers of dimensions up to $12 \mathrm{~cm}$ in diameter. The nitrogen gas and temperature stabilized environment is usually maintained during profiling measurements. Also, the scan regime of wafer edge is foreseen in this instrument, which is implemented using a needle-tip MW antenna probe intersecting with a single mode fibre tip. The slit MW antenna of 10-100 $\mu \mathrm{m}$ width was employed for scanning of the laser beam excited area. The excess carrier excitation was implemented using 500 ps laser pulses. The IR $\left(\lambda_{\text {ex }}=1062 \mathrm{~nm}\right)$ excitation was implemented through a MW slit. The laser light spot was transferred using a single-mode fibre mounted within the MW antenna. The simplified Vilnius University proprietary made carrier lifetime profiler VUTEG- (a)

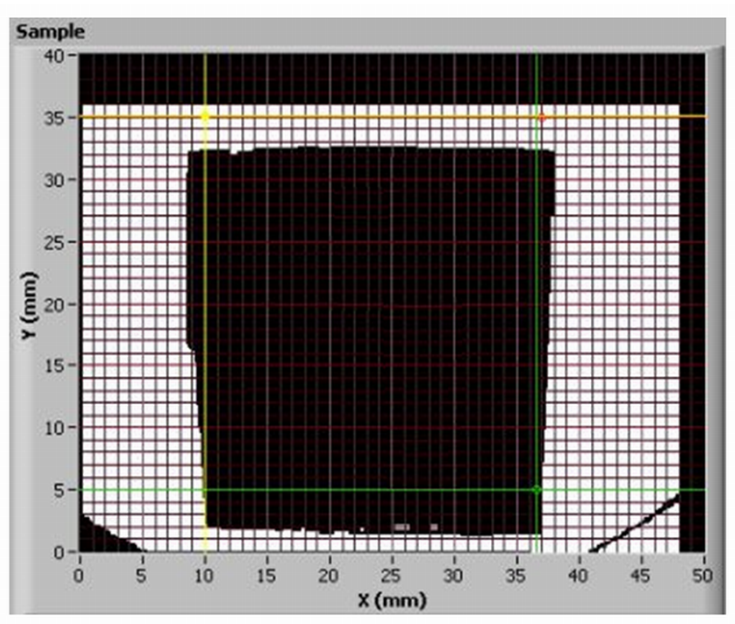

(b)

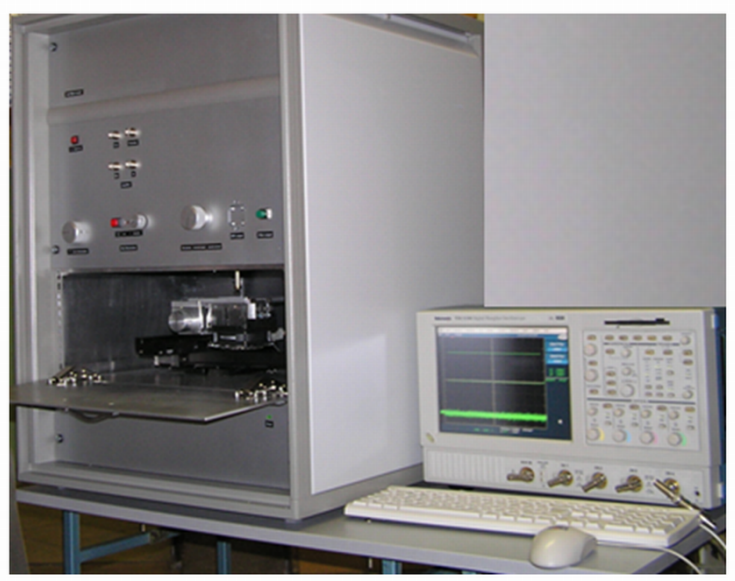

(c)

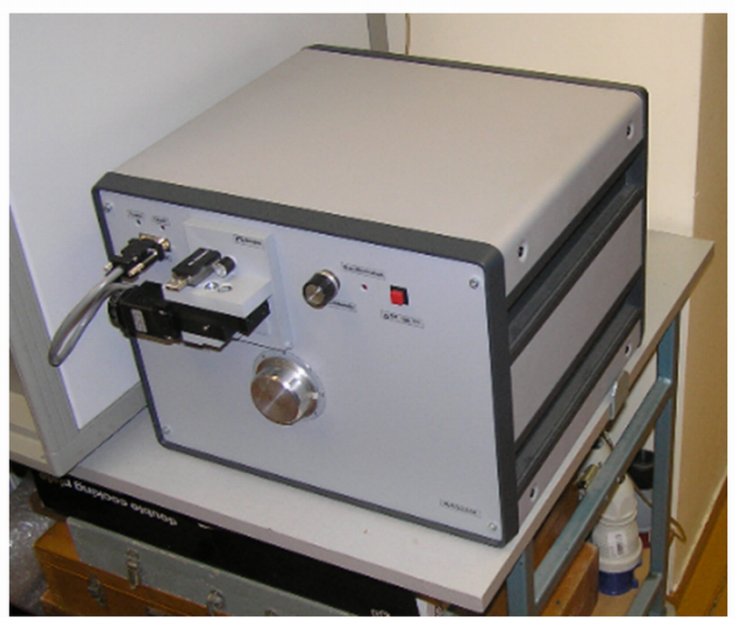

Fig. 2. Size and position coordinates (of wafer $30 \times 30 \mathrm{~mm}$ fragment) in lifetime scanning experiments are controlled using CCD imaging within an instrument VUTEG-4 (a). The Vilnius University proprietary made instruments VUTEG-4 (b) and VUTEG-5-AIDA (c).

5-AIDA (Fig. 2(c)) is installed at CERN. The latter instrument is devoted to rapid examination of the as-irradiated Si materials residing in harsh environment. There, the $1 \mathrm{D}$ lateral scanning is commonly performed, while the perpendicular rotation 
of sample fragments of dimensions $\sim 11 \mathrm{~mm}$ enables one to have a cross-profile within sample diameter direction.

Lateral profiling of the irradiated areas using the Si and MW-PC carrier lifetime scanning technique is simply applicable in the diagnostics of penetrative particle beams. For rather low energy protons with short ranging $(<30 \mu \mathrm{m})$, the depth inhomogeneity of radiation defect distribution complicates the reliable extraction of local fluence values. Sometimes the depth profiling by using the wafer edge scanning regime can be applied [12], however the high resolution lateral profiling of beams is then impossible.

\subsection{Fluence scans using scintillation intensity variations in $G a N$ wafer fragments}

Scanning of the scintillation signals is a good alternative for profiling of the short-range particle beams. The rather thin GaN layers with $L_{\mathrm{p}} \sim 26 \mu \mathrm{m}$ stopping range for $\leq 2 \mathrm{MeV}$ protons have been employed for accumulation of the definite dose where the depth homogeneous distribution of radiation defects can be obtained. The consequent changes of the scintillation spectrum or single spectral peak intensity are commonly profiled. The calibrated fluence dependent variation of yellow-green (YG) luminescence intensity (Fig. 3) of the $\sim 3 \mu \mathrm{m}$ thick MOCVD grown

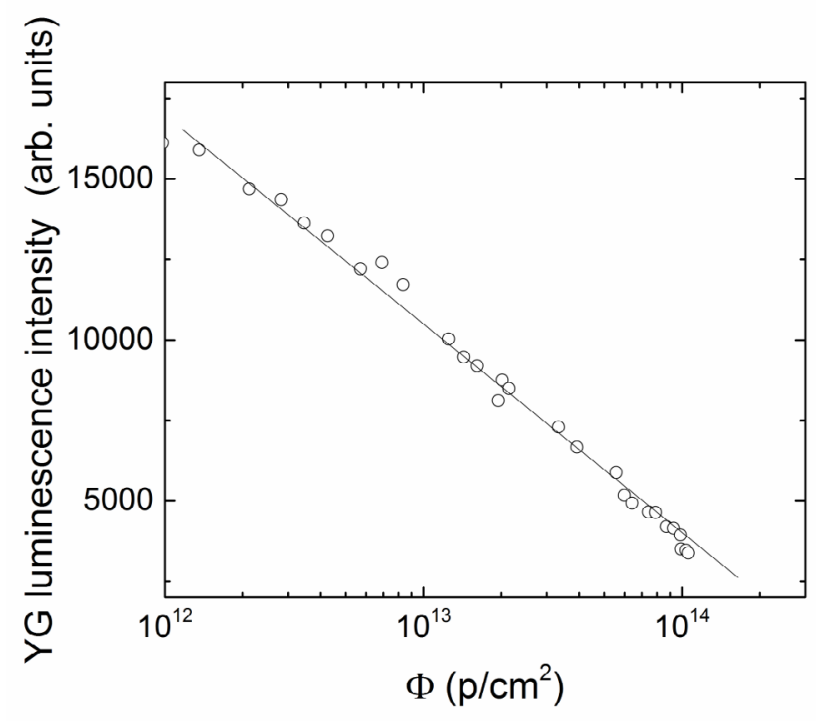

Fig. 3. The calibration characteristic for the shortrange particle beam profiling based on YG luminescence intensity variations dependent on $1.6 \mathrm{MeV}$ proton fluence.
GaN layer is initially measured to extract fluence values. The measurements of the calibration curve are performed by the in situ or stepped spectroscopy [13] of the GaN luminescence variations under successive accumulation of fluence within a laterally homogeneous irradiation spot. The proton beam of a diameter that exceeds the dimensions of the GaN wafer fragment is commonly applied to have a nearly homogeneously irradiated sensor area. It can be noticed in Fig. 3 that a rather narrow dynamic range of fluences, in comparison with Fig. 1, can be covered within the calibration curve when direct control of scintillation intensity is applied. The same GaN sensor material is then exploited for scanning of a rather narrow beam profile (Fig. A). The latter procedure is implemented ex situ by using ultraviolet (UV) short pulse (400 ps) laser excitation.

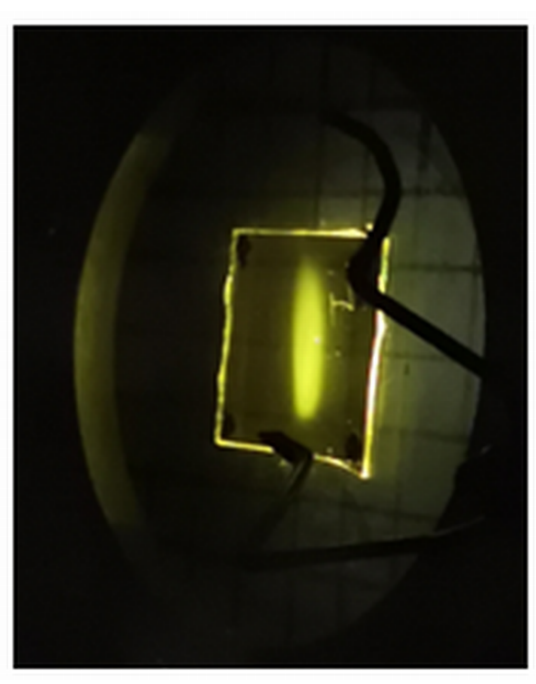

Fig. 4. The narrow beam of 1.6 $\mathrm{MeV}$ proton excited YG luminescence image. The GaN wafer fragment exceeds dimensions of the proton beam.

Profiling of the rather narrow beam trace within an irradiated $\mathrm{GaN}$ wafer fragment is commonly performed by lateral scans of YG scintillation in a GaN sensor using the optical arrangement sketched in Fig. 5(a). An ultraviolet laser STA-3H emitting the $351 \mathrm{~nm}$ light was employed for excitation of $\mathrm{GaN}$ YG photoluminescence. The PL response filtered from the laser beam is collected into a UV range fibrescope and transmitted to a spectrophotometer. An Avantes grating spectrophotometer was exploited to accumulate the spectrally dispersed PL response. 

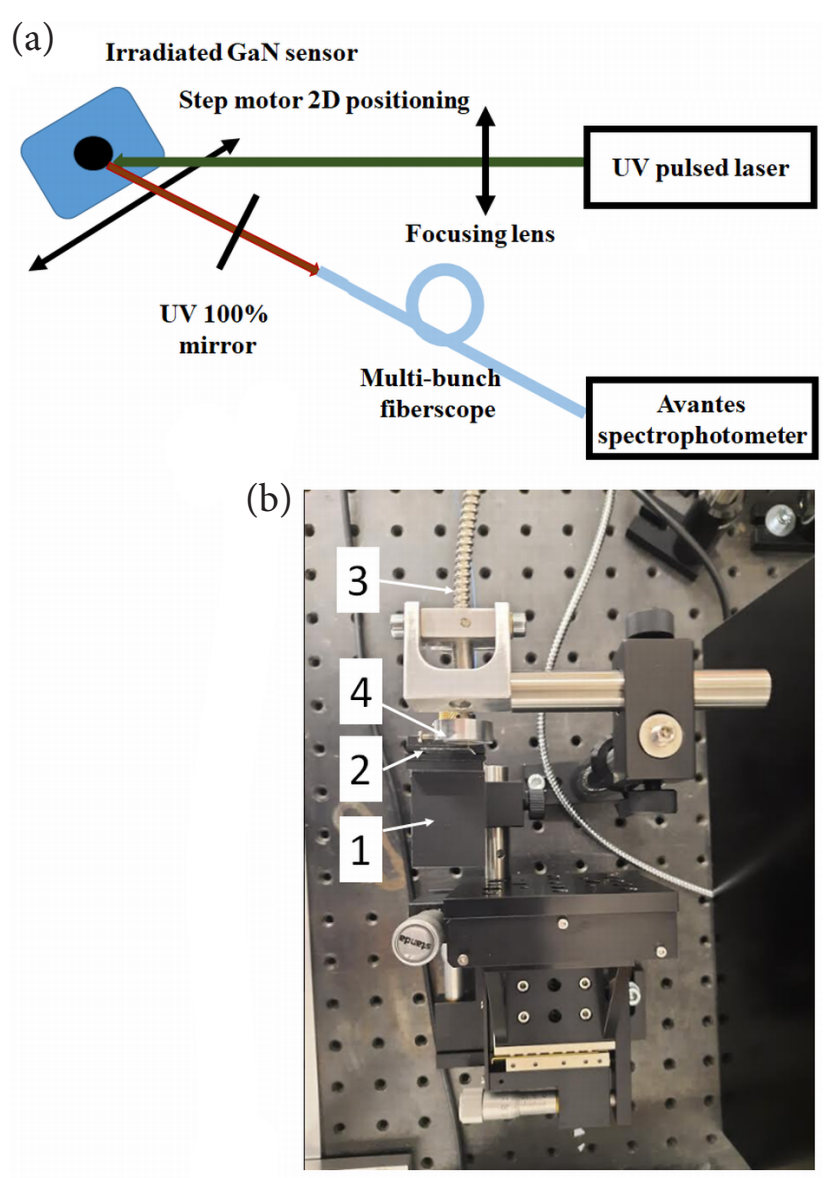

Fig. 5. (a) Sketch of the instrumentation for the profiling of YG photoluminescence (PL) in a proton beam irradiated $\mathrm{GaN}$ sensor. The local excitation with a laser light spot dimension of $\sim 10 \mu \mathrm{m}$ is implemented using a single-mode fibre. The YG scintillation light is collected by using a multi-bunch fibrescope and displayed by an Avantes spectrophotometer. Several elements are employed to reject the UV laser illumination of the spectrometer slit. The scans are performed by using $2 \mu \mathrm{m}$ precision steppers. (b) An image of the experimental arrangement of beam profiler using scintillation scans: sample holder (1), irradiated GaN sensor (2), multi-bunch fibrescope (3), UV 100\% mirror (4).

\section{Recorded profiles of hadron beams}

The $2 \mathrm{D}$ profile of carrier recombination lifetime distribution within the FZ Si wafer fragment of $30 \times 30 \mathrm{~mm}$ dimensions, irradiated with relativistic of $26 \mathrm{GeV} / \mathrm{c}$ protons, is illustrated in Fig. 6 (a). This lateral distribution has been scanned with spatial resolution of several microns using an instrument VUTEG-4. The fluence values were extracted using the recombination lifetime dependence on the penetrative hadron irradiation fluence illustrated in
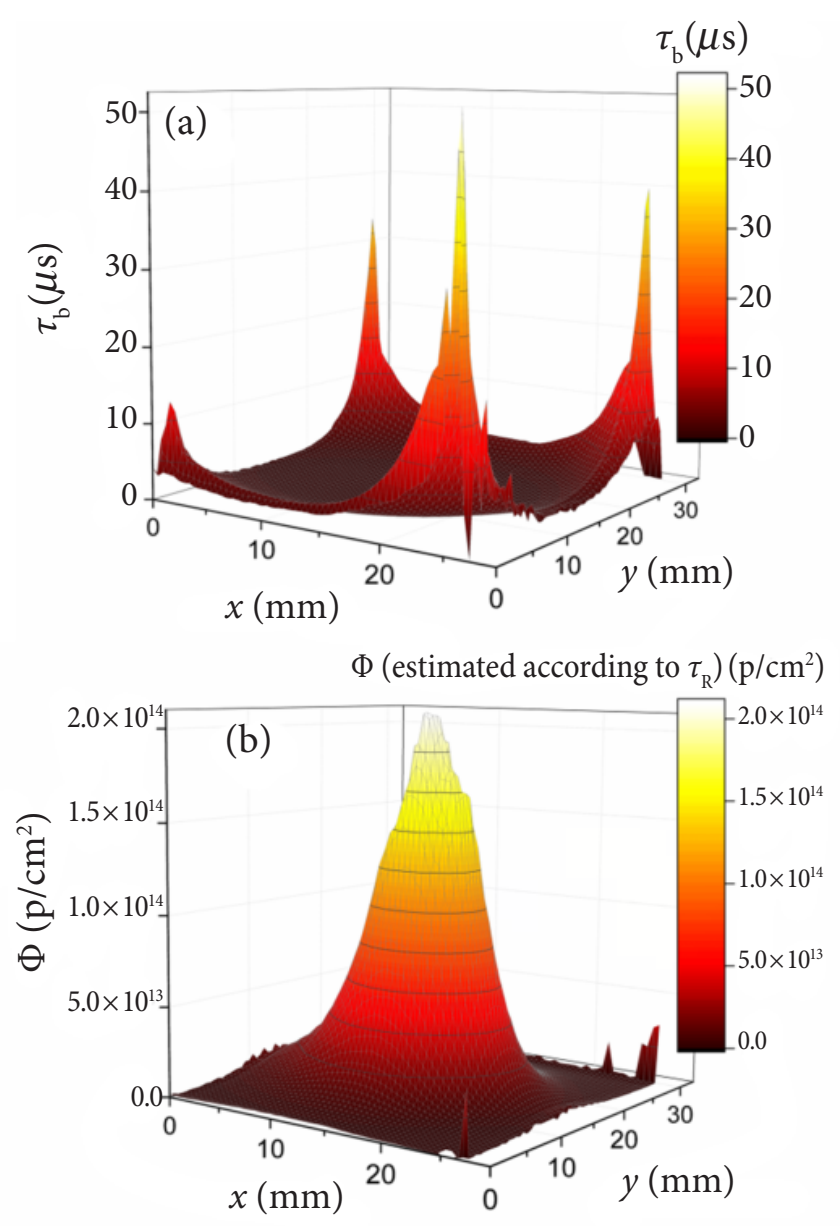

Fig. 6. The $2 \mathrm{D}$ profiles of carrier recombination lifetime (a) and fluence (b) in the $26 \mathrm{GeV} / \mathrm{c}$ proton beam irradiated $\mathrm{Si}$ wafer fragment of dimensions $30 \times 30 \mathrm{~mm}$, scanned using a VUTEG-4 instrument.

Fig. 1. This profile is illustrated in Fig. 6(b). It shows the bell-shape curve. The particle beam profile is commonly approximated by the Gauss function [ 1 , 3] due to the variation of accelerated particle velocities within a beam.

The profiles of fluence variations within $X$ and $Y$ sections crossing the beam centroid are illustrated in Fig. 月. There, the asymmetry within the shape of the $X$ section can be noticed in Fig. Z(a), while the $Y$ section is close to the Gaussian curve shape (Fig. $\#($ (b)). The latter fluence distribution profile $\Phi(Y)$ can be easily approximated by using the 1D Gauss function, read as [3]

$$
\Phi(Y)=\frac{N}{\sqrt{2 \eta \sigma_{Y}}} \exp \left[-\frac{\left(Y-Y_{0}\right)^{2}}{2 \sigma_{Y}^{2}}\right] .
$$

Here, $N$ is the quantity of radiation defects accumulated within the centroid (close to the point $X_{0}, Y_{0}$ ) 
$X$ sections of the fluence distribution within the $26 \mathrm{GeV} / \mathrm{c}$ irradiated $\mathrm{Si}$

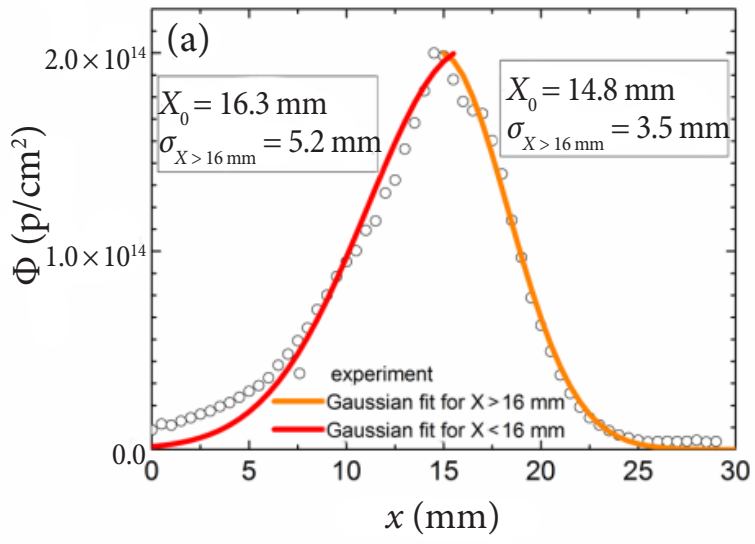

$Y$ sections of the fluence distribution within the $26 \mathrm{GeV}$ irradiated $\mathrm{Si}$

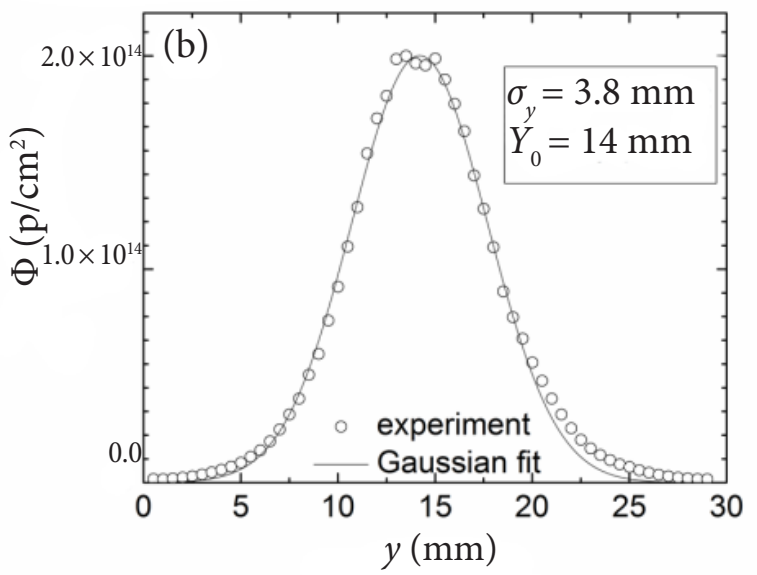

Fig. 7. $X$ (a) and $Y$ sections (b) of the fluence distribution within the $26 \mathrm{GeV} / \mathrm{c}$ proton beam irradiated Si wafer fragment.

of the irradiation beam, and $\sigma_{Y}$ is the effective crosssection of the Gaussian function. Consequently, the $2 \mathrm{D}$ profile is described by the function

$$
\Phi(X, Y)=\frac{N}{2 \eta \sigma_{X} \sigma_{Y}} \exp \left\{-\left[\frac{\left(X-X_{0}\right)^{2}}{2 \sigma_{X}^{2}}+\frac{\left(Y-Y_{0}\right)^{2}}{2 \sigma_{Y}^{2}}\right]\right\} .
$$

A fit of the $\Phi(Y)$ profile obtained for the $26 \mathrm{GeV} / \mathrm{c}$ proton beam is represented by a solid curve in Fig. 7 (b). This fitting procedure enables one to get parameters of the beam, as $N$ and $\sigma_{Y}$. However, the beam profile within the $X$ section cannot be approximated by a single parameter $\sigma_{X}$. The beam $X$ direction movements during accumulation of irradiation damage led to a significant asymmetry of the $\Phi(X)$ beam profile. Then, different values of the beam effective width should be assumed, as $\sigma_{X}=5.2 \mathrm{~mm}$ for $X<16 \mathrm{~mm}$ and $\sigma_{X}=3.5 \mathrm{~mm}$ for
$X>16 \mathrm{~mm}$. The latter value of $\sigma_{X}=3.5 \mathrm{~mm}$ is close to that $\left(\sigma_{Y}=3.8 \mathrm{~mm}\right)$ determined from $Y$ section fits. The $\sigma_{X, Y}$ parameters outline the beam full width $\left(S_{X, Y}\right)$ at half maximum of its amplitude (FWHM), and for Gaussian beams it is the well-known relation $S_{X, Y}=2.35 \sigma_{X, Y}$, respectively [3].

The impact of beam stability is less important when an instantaneous particle flux is controlled by a beam profile monitor. The comparison of $2 \mathrm{D}$ beam profiles scanned by measurements of accumulated fluence and by the beam profile monitor, installed at CERN, is illustrated in Fig. 8. The fluence has been re-calculated using the flux data in Fig. 8(b), to be able to compare the beam profiles scanned by different techniques and instruments. Also, the beam profile monitor was significantly
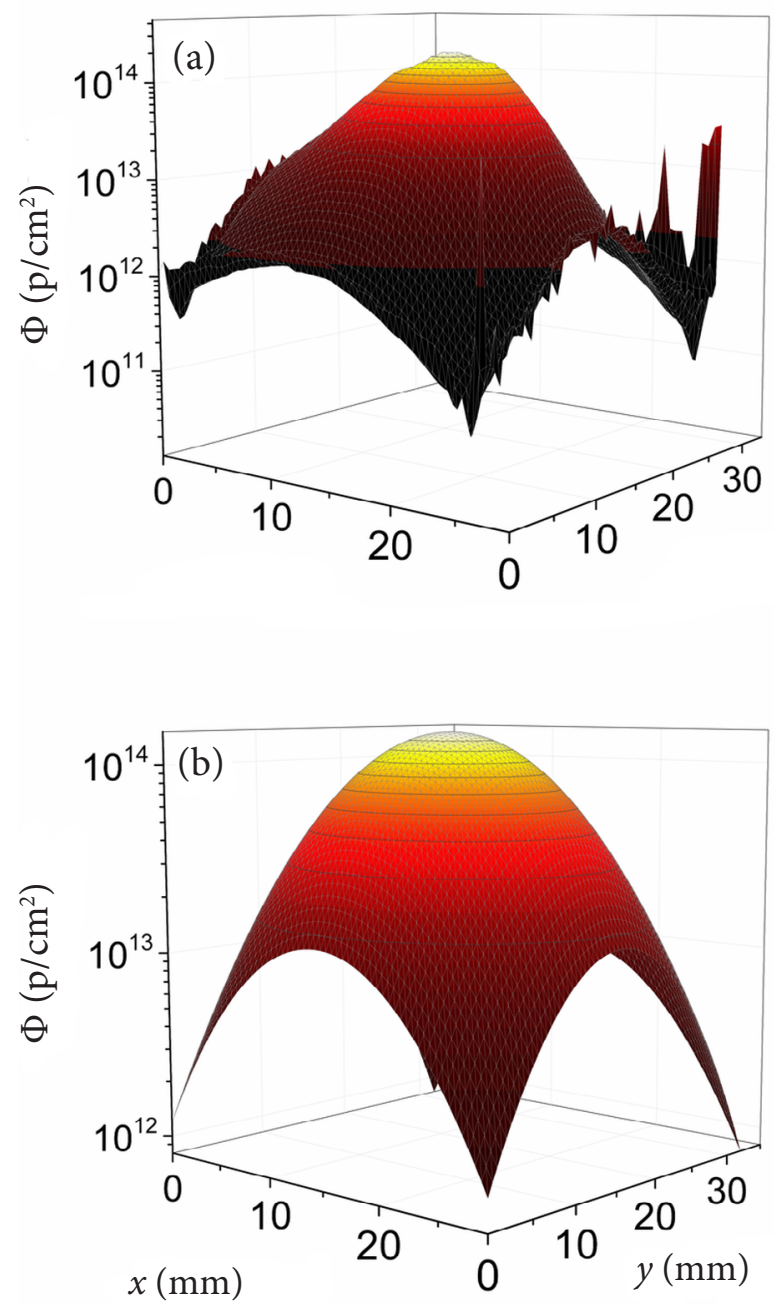

Fig. 8. Comparison of the $2 \mathrm{D}$ fluence distribution profiles measured within the $26 \mathrm{GeV} / \mathrm{c}$ proton beam irradiated Si wafer fragment by employing a VUTEG-4 instrument (a) and using a proton beam profiler (b) installed at CERN. 
shifted (about $20 \mathrm{~cm}$ ) from the location of $\mathrm{Si}$ wafer fragment within the impinging particle beam. It can be noticed in Fig. 8(b) that a rather symmetric and Gaussian shaped beam has been recorded by using the CERN beam profile monitor. Nevertheless, the difference in fitted beam parameters has been revealed as $\sigma_{X}=6.6 \mathrm{~mm}, \sigma_{Y}=7.0 \mathrm{~mm}, X_{0}=16.0 \mathrm{~mm}$ and $Y_{0}=15.4 \mathrm{~mm}$. These values are also close to that $\left(\sigma_{X}=5.2 \mathrm{~mm}\right)$ obtained from the profile fitting

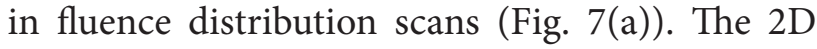
beam shape in Fig. 8(a), recorded by fluence scans, seems to be spiked relative to the flattened one obtained using the beam profile monitor, in Fig. 8(b). Nonetheless, $\Phi_{0} \cong N$ values of $2 \times 10^{14} \mathrm{~cm}^{-2}$ fluence in the beam centre were obtained using both instruments, the VUTEG-4 (together with FZ Si sensors) and CERN beam profile monitor.

The $8 \mathrm{MeV}$ protons remain the penetrative particles for $\sim 300 \mu \mathrm{m}$ thick Si wafers. Thereby, the VUTEG-4 instrument has been applied for $8 \mathrm{MeV}$ irradiated MCZ Si wafer fragments. Such a proton beam was emitted by a Tandem accelerator at Helsinki University. The $X$ section of the beam appeared to be close to the Gaussian shape (Fig. 9), shown by a solid curve.

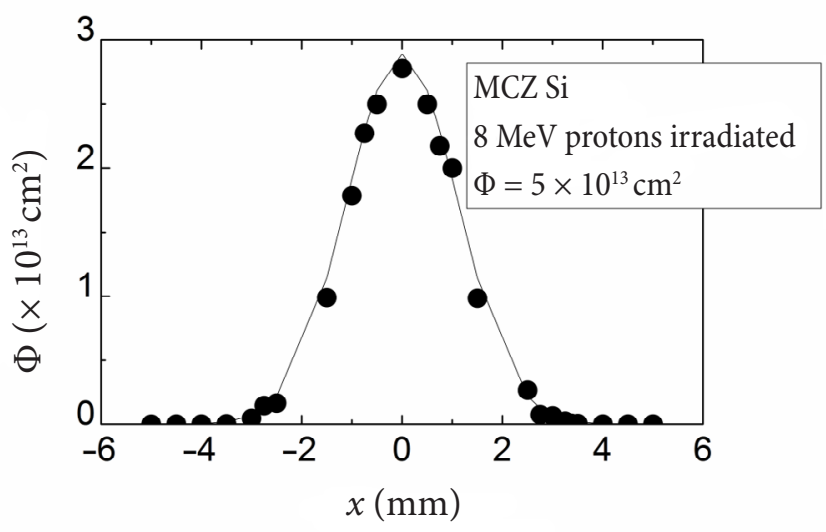

Fig. 9. The 1D fluence distribution profile measured by the VUTEG-4 instrument within the $8 \mathrm{MeV}$ proton beam irradiated $300 \mu \mathrm{m}$ thick MCZ Si wafer fragment.

However, the shape of pion beams, recorded at CERN, appeared to be clearly non-Gaussian (Fig. 10(b)). There, the single-directional recombination lifetime scans (Fig. 10(a)) by VUTEG-5-AIDA instrument were performed using a narrow $(\leq 1 \mathrm{~cm})$ FZ Si sensor (wafer fragment). Fitting of the lateral fluence distribution within the pion irra-
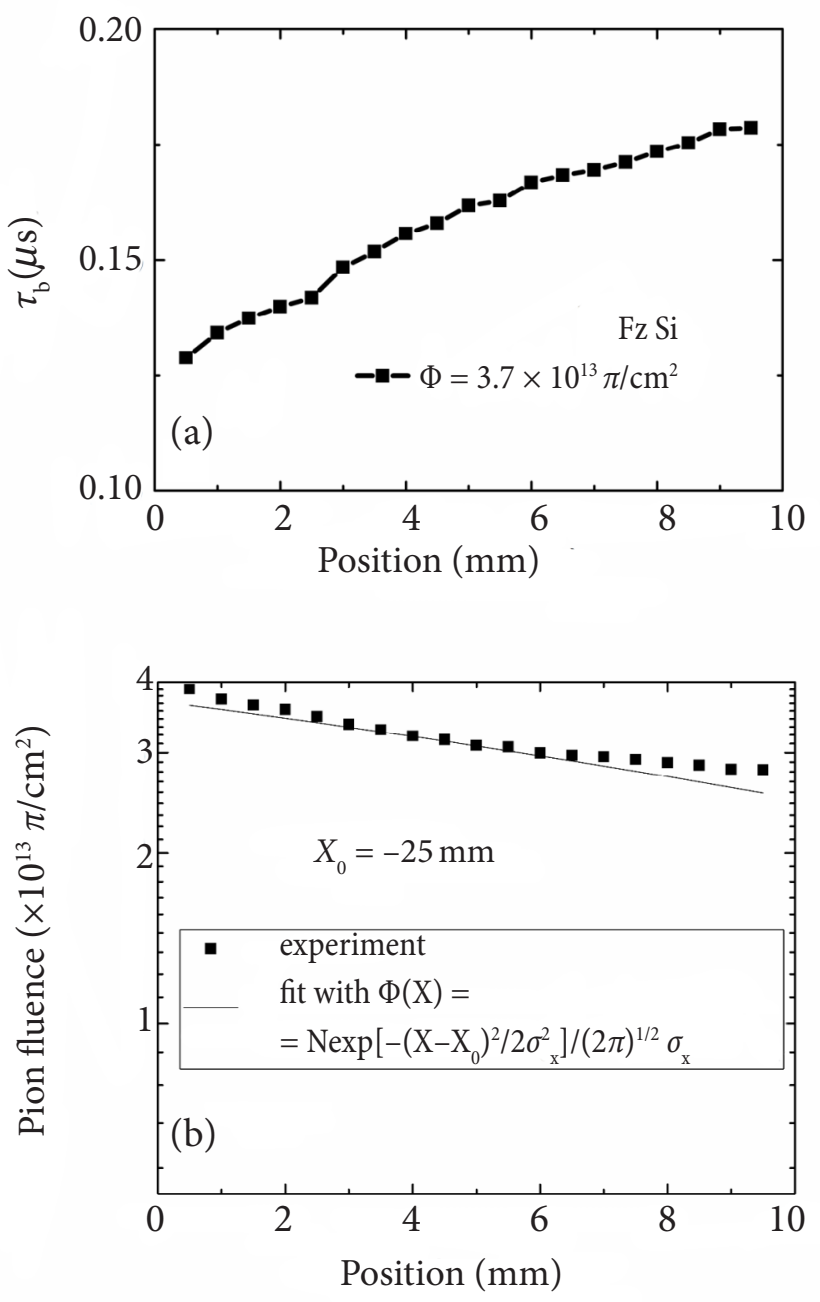

Fig. 10. The $1 \mathrm{D}$ profiles of carrier recombination lifetime (a) and fluence (b) in the $300 \mathrm{MeV} / \mathrm{c}$ pion irradiated $\mathrm{Si}$ wafer fragment of dimensions $10 \times 10 \mathrm{~mm}$ and scanned using the VUTEG-5-AIDA instrument. In Fig. 10(b) the fluence distribution profile (symbols) and the best fit (solid curve) using the Gauss function are shown.

diated Si wafer fragment sets the centroid position $\left(X_{0}=-25 \mathrm{~mm}\right)$ outside the sensor area.

The luminescence intensity profile obtained in the $1.6 \mathrm{MeV}$ proton irradiated $3 \mu \mathrm{m}$ thick $\mathrm{GaN}$ layer, MOCVD grown on sapphire, is illustrated in Fig. 11(a). The stopping range of $L_{\mathrm{p}} \sim 26 \mu \mathrm{m}$ of 1.6 $\mathrm{MeV}$ protons, evaluated using transport of ions in matter (TRIM) simulations, significantly exceeds the GaN layer thickness $d=3 \mu \mathrm{m}$. Thereby, depth-homogeneous introduction of radiation defects can be assumed. The fluence distribution profile can then be restored (Fig. 11(b)) using the calibration curve (Fig. 3) which relates the YG scintillation intensity of the same GaN material 

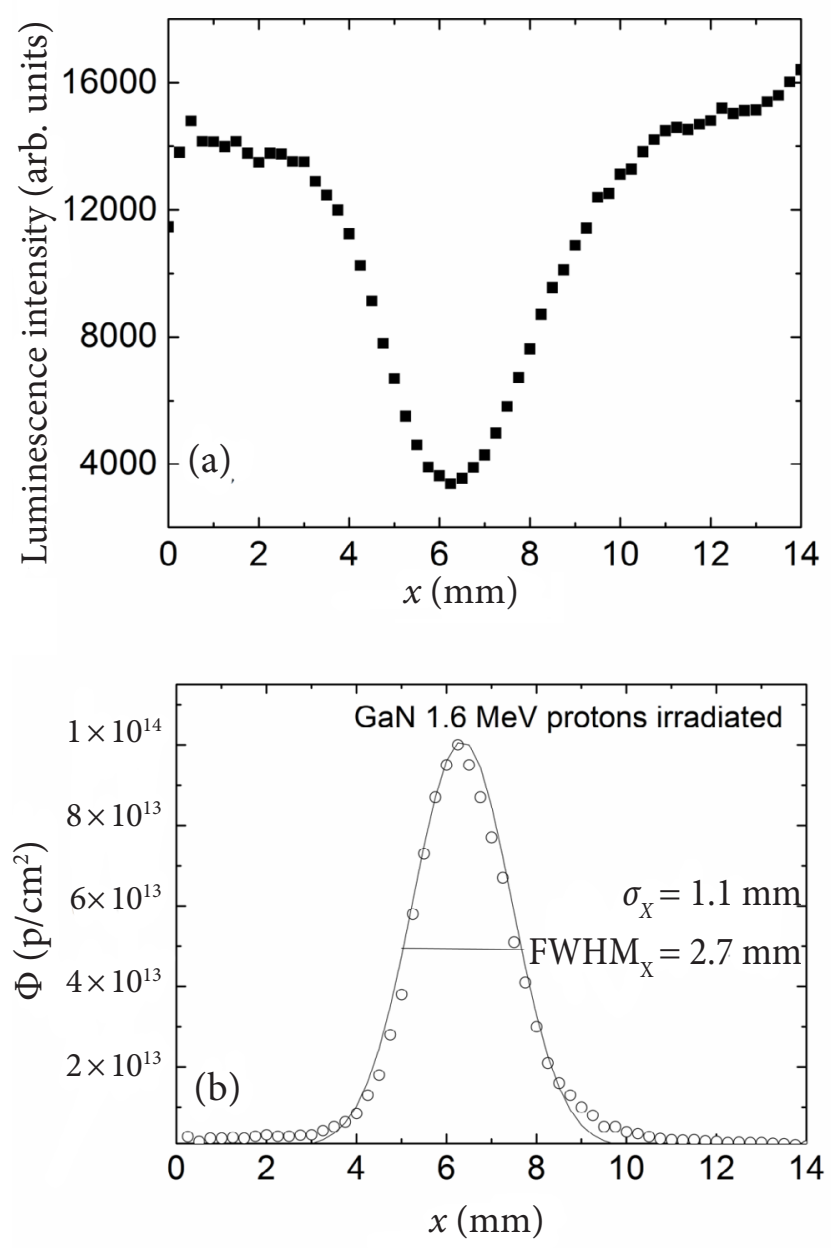

Fig. 11. The 1D profiles of YG luminescence distribution within a $3 \mu \mathrm{m}$ thick MOCVD GaN layer irradiated with $1.6 \mathrm{MeV}$ protons (a) and of fluence (b) extracted using a calibration curve, illustrated in Fig. 3. In Fig. 11(b), the fluence distribution profile (symbols) fitted using the Gauss function (a solid curve) is represented.

and the accumulated fluence. The rather symmetric $X$-directional cross-section of the focused $1.6 \mathrm{MeV}$ proton beam was examined. Whereas, the proton beam can be outstretched (as shown in Fig. 4) by the focusing system of a Tandem accelerator. It can be noticed in Fig. 11.(b) that the UV laser recovered luminescence intensity reproduces well the fluence distribution of a Gaussian shape. Then, the beam parameter $F W H M_{X}=2.7 \mathrm{~mm}$ has been extracted. The $F W H M_{X}$ and $\Phi$ parameters appeared to correlate well with the predicted characteristics, estimated using the beam current, exposure time and other irradiation data [14]. Thereby, such a scintillation technique is reliable for the in situ quantitative control of irradiation characteristics.

\section{Summary}

The beam profiling techniques based on dosimetry of the hadron irradiated $\mathrm{Si}$ and $\mathrm{GaN}$ sensors have been demonstrated. It is shown that the penetrative particle regime, with $L_{\mathrm{p}} \gg d$, should be employed to appropriately record $2 \mathrm{D}$ fluence distribution profiles. Therefore, for beams of rather low energy particles thin sensors are preferable. Then, the scintillation techniques are desirable to have recordable responses from thin sensors. The Gaussian shape beams are commonly recorded. However, the fluence measurement based techniques enable one to reveal the asymmetry of beams due to instability of beam position during prolonged exposures. These techniques also allow the profiling of neutral particles, such as neutrons [15], based on the universal recombination lifetime dependence on hadron irradiation fluence in high purity Si materials.

\section{Acknowledgements}

This research was partially funded by the European Regional Development Fund according to the supported activity 'Research Projects Implemented by World-class Researcher Groups' under Measure No. 01.2.2-LMT-K-718-1-0013. The authors are indebted to I. Mateu, M. Moll and S. Martens for proton irradiations and proton beam characterization at CERN. This research is devoted to the 80 -year Anniversary of Professor J.V. Vaitkus.

\section{References}

[1] G. Kube, in: Proceedings of the 2018 CERN Accelerator School's Course on Beam Instrumentation (CERN, Geneva) pp. 18-119, arXiv-2005.08389.

[2] K. Wittenburg, in: Proceedings of the CERN Accelerator School's Course on High Power Hadron Machines, ed. R. Bailey (CERN, Geneva, 2013) pp. 251-308.

[3] E. Bravin, in: Proceedings of the 2018 CERN Accelerator School's Course on Beam Instrumentation (CERN, Geneva) pp. 318-354.

[4] B. Boyer, R. Cornat, E. Delagnes, Y. Geerebaert, O. Gevin, F. Haddad, C. Koumeir, F. Magniette, P. Manigot, F. Poirier, et al., Development of an ultra thin beam profiler for charged particle 
beams, Nucl. Instrum. Methods Phys. Res. A 936, 29-30 (2019).

[5] P. Ausset, S. Bousson, D. Gardès, A.C. Mueller, B. Pottin, R. Gobin, G. Belyaev, and I. Roudskoy, in: Proceedings of 8th European Particle Acceleration Conference EPAC 2002 (European Physical Society, Geneva, 2002) pp. 1840-1842.

[6] V.E. Scarpine, Transverse beam shape measurements of intense proton beams using optical transition radiation, Phys. Procedia 37, 21232128 (2012).

[7] A. Nause, E. Dyunin, R. Ianconescu, and A. Gover, Exact theory of optical transition radiation in the far and near zones, J. Opt. Soc. Am. B 31(10), 2438-2445 (2014).

[8] C. Belver-Aguilar, S. Braccini, T.S. Carzaniga, A. Gsponer, P.D. Häffner, P. Scampoli, and M. Schmid, A novel three-dimensional non-destructive beam-monitoring detector, Appl. Sci. 10(22), 8217 (2020).

[9] N.P. Dover, M. Nishiuchi, H. Sakaki, M.A. Alkhimova, A.Ya. Faenov, Y. Fukuda, H. Kiriyama, A. Kon, K. Kondo, K. Nishitani, et al., Scintillatorbased transverse proton beam profiler for laser-plasma ion sources, Rev. Sci. Instrum. 88, 073304 (2017).

[10]M. Cavallonea, A. Flaccoa, and V. Malka, Shaping of a laser-accelerated proton beam for radiobiology applications via genetic algorithm, Phys. Med. 67, 123-131 (2019).
[11]E. Gaubas, E. Simoen, and J. Vanhellemont, Review-Carrier lifetime spectroscopy for defect characterization in semiconductor materials and devices, ECS J. Solid State Sci. Technol. 5, P3108-P3137 (2016).

[12]E. Gaubas, T. Ceponis, A. Uleckas, J. Vaitkus, K. Žilinskas, V. Kovalevskij, M. Gaspariunas, and V. Remeikis, In situ analysis of the carrier lifetime in silicon during implantation of $1.5 \mathrm{MeV}$ protons, Lith. J. Phys. 50(4), 427-433 (2010).

[13]E. Gaubas, T. Ceponis, A. Jasiunas, V. Kovalevskij, D. Meskauskaite, J. Pavlov, V. Remeikis, A. Tekorius, and J. Vaitkus, Correlative analysis of the in situ changes of carrier decay and proton induced photoluminescence characteristics in chemical vapour deposition grown GaN, Appl. Phys. Lett. 104, 62104 (2014).

[14]P.J. Sellin and J. Vaitkus, New materials for radiation hard semiconductor detectors, Nucl. Instrum. Methods Phys. Res. A 557, 479-489 (2006).

[15]E. Gaubas, T. Ceponis, A. Jasiunas, A. Uleckas, J. Vaitkus, E. Cortina, and O. Militaru, Correlated evolution of barrier capacitance charging, generation and drift currents and of carrier lifetime in Si structures during $25 \mathrm{MeV}$ neutrons irradiation, Appl. Phys. Lett. 101, 232104 (2012).

\title{
PROTONŲ PLUOŠTELIŲ PROFILIAVIMAS İTĖKIO SKENERIAIS
}

\author{
L. Deveikis a , J.V. Vaitkus a , T. Čeponis a , M. Gaspariūnas ${ }^{\text {b }, ~ V . ~ K o v a l e v s k i j ~ a ~, ~ b, ~ V . ~ R u m b a u s k a s ~ a, ~}$ \\ E. Gaubas ${ }^{\text {a }}$ \\ a Vilniaus universiteto Fotonikos ir nanotechnologiju institutas, Vilnius, Lietuva \\ ${ }^{\mathrm{b}}$ Fiziniu ir technologiniu mokslu centras, Vilnius, Lietuva
}

\begin{abstract}
Santrauka
Darbe aptartos protonų pluošteliu charakterizavimo technologijos pasitelkiant $\mathrm{Si}$ ir $\mathrm{GaN}$ sensorius bei apšvitos ịtèkio skenavimo būdus. Šie būdai yra pagrịsti krūvininkų gyvavimo trukmès didžiavaržiame Si ir žaliai geltonosios GaN liuminescencijos intensyvumo pasiskirstymo kontrole. Parodyta, kad egzistuoja gana universalios charakteristikos, nusakančios radiacinių defektų koncentracijos, krūvininkų gyvavimo trukmès
\end{abstract}

ir liuminescencijos intensyvumo ryšius su Si bei GaN medžiagų apšvitos hadronais iteekiu. Šios charakteristikos yra pasitelktos ịtekio pasiskirstymo profiliams identifikuoti. Parodyta, kad daugeliu atveju įvairiu dalelių greitintuvų formuojamų pluoštelių forma gali būti aproksimuojama Gauso funkcija. Aptartos šiu metodų taikymo galimybès elektringiems ir neutraliems dalelių pluoštams kiekybiškai charakterizuoti. 